\title{
ANALYSIS ON ENRICHMENT OF AQUATIC PLANTS RESPONSE TO DIFFERENT HEAVY METAL IONS IN POLLUTED WATER- TAKING DUCKWEED AS AN EXAMPLE
}

\author{
OUYANG, Z. ${ }^{1,2}-$ YANG, Z. ${ }^{1,2}-$ FENG, G. ${ }^{1,2}-$ ZHAO, Y..$^{1 *}$ \\ ${ }^{I}$ Key Laboratory of Bio-Resources and Eco-Environment, Ministry of Education, College of Life \\ Sciences, Sichuan University, Chengdu 610064, China \\ ${ }^{2}$ Chengdu Institute of Biology, Chinese Academy of Sciences, Chengdu 610064, China \\ *Corresponding author \\ e-mail:zhaoyun@scu.edu.cn \\ (Received $15^{\text {th }}$ Jun 2018; accepted $2^{\text {nd }}$ Aug 2018)
}

\begin{abstract}
In order to improve the quality of water, the enrichment of different heavy metal ions by aquatic plants is studied - taking duckweed as an example. The site of the experiment is in Sichuan University of China, mainly from the following aspects of research: the heavy metal content in water, the heavy metal content in duckweed, chlorophyll content, adsorption capacity of Cadmium ions in different concentrations of nitric acid solution, enrichment capacity of Cadmium ion and the relationship between heavy metal content in duckweed and that of water. The study shows that the aquatic plants such as duckweed have a strong enrichment to $\mathrm{Cu}, \mathrm{Pb}$ and $\mathrm{Zn}$ in the complex water body of heavy metals $\mathrm{Cu}, \mathrm{Pb}$ and $\mathrm{Zn}$, and their enrichment ability is higher than that of the water plants. With the increase of $\mathrm{Cd}^{2+}$ concentration, the content of chlorophyll a and b in duckweed decreased significantly, and the decline is increased with the increase of $\mathrm{Cd}^{2+}$ concentration. In $3 \mathrm{mg} / \mathrm{L}$ Cadmium nitrate solution, duckweed has a maximum absorption rate of $\mathrm{Cd}^{2+}$ reaching $87 \%$, the adsorption of duckweed decreased with increasing concentration and the enrichment of $\mathrm{Cd}^{2+}$ in duckweed showed a nonmonotonic curve with the increase of treatment time. The concentration of $\mathrm{Cd}^{2+}$ in the duckweed of $8 \mathrm{~d}$ reached the maximum value $(1.6 \mathrm{mg} / \mathrm{g})$, and the concentration of $\mathrm{Cd}^{2+}$ is reduced in the 9-12d duckweed, the concentration of heavy metals in water is significantly correlated with the concentration of $\mathrm{Cu}, \mathrm{Pb}, \mathrm{Zn}$ and $\mathrm{Mn}$ in aquatic plants duckweed. The method can effectively analyze the supposed enrichment. The sensitivity of duckweed can be used to detect changes of heavy metals in water, which can be used as an bioindicator of environmental pollution. At the same time, the accuracy of heavy metal determination by this method is high.
\end{abstract}

Keywords: duckweed, heavy metal ions, enrichment, chlorophyll content, determine

\section{Introduction}

Since 1970s, with the development of industry and agriculture, all kinds of untreated sewage have been discharged into lakes and rivers, and the amount of heavy metals in the water increased. Most of these have the characteristics of enduring hazards, geochemical recycling and ecological risk. Aquatic plants such as duckweed are part of the ecosystem, and they play an important role in material circulation, migration of elements and purification of sewage. A large number of studies have shown that the heavy metal content in water has a positive correlation with the heavy metal content in aquatic plant, the amount of many of elements in duckweed are hundreds of times as much as these in the water, therefore, the content of heavy metals in duckweed is used to reflect the level of heavy metals in water ( $\mathrm{Li}$ and Wang, 2016). The heavy metals absorbed by aquatic plants are mainly derived from their growing environment. If the concentration of heavy metals in water increases, the content heavy metals in aquatic plants will also increase. That is to say, the higher the heavy metals level in the pollution, the higher the concentration of heavy metals in plants. The toxic effect of 
metals on duckweed has been studied by scholars. After sampling, different heavy metal ions were analyzed to compare the different enrichment of duckweed. The analysis basis for sewage treatment is provided and improves the quality of water (Unsal and Soylak, 2015).

Tang et al. in order to screen duckweed varieties which can efficiently remove heavy metal Cadmium from water and accumulate biomass rapidly, 12 duckweed varieties with tolerance to $30 \mathrm{mg} / \mathrm{L} \mathrm{Cd}^{2+}$ concentration are screened again at $0.5 \mathrm{mg} / \mathrm{L}$ and $10 \mathrm{mg} / \mathrm{L} \mathrm{Cd} \mathrm{Cd}^{2+}$ concentrations. The best variety of Landoltia punctata ZH0049 is obtained. At the same time, the relationship between the change of chlorophyll content and the concentration of Cadmium stress are analyzed. However, the results of this method were not accurate (Tang et al., 2015a); Fan et al. take duckweed as the research object and applied phosphate to study the response mechanism of antioxidant enzyme system and the enrichment ability of Uranium under different concentration of Uranium stress. There is a problem that the research time is too long (Fan et al., 2018). In view of the above problems, the enrichment of different heavy metal ions by aquatic plants is studied, taking duckweed as an example.

\section{Materials and methods}

\section{Materials}

Duckweed samples of size $1-2 \mathrm{~mm}(1 \mathrm{~mm} \times 1 \mathrm{~mm})$ are collected in the lake water, specifically in TaiHu Lake (120 $36^{\prime} \mathrm{E}$ and $\left.31^{\circ} 22^{\prime} \mathrm{N}\right)$, JiangSu province. The samples are collected by duckweed fishing vessel with a sample quantity of $5 \mathrm{~kg}$. 150 clean plastic drums with a volume of $14 \mathrm{~L}$ are selected. The human nutrient solution is injected into each barrel without heavy metal ions to be measured, and an open foam plate is placed on the barrel as the growth carrier of the plant. Duckweed is transferred into three round holes of foam carrier, and its root is immersed in 1/10 Hoagland solution. The growth and management of plants are cultivated in the open air, watered every 3 days and supplemented with 1/10 Hoagland solution, which kept the plants well ventilated and illuminated. Plant samples are collected after 15 days.

Finally, the collected samples will be rinsed repeatedly with tap water and distilled water. After sucking the water with the absorbent paper, the fresh weight is measured. Then it was dried in a ventilated and dry place, and the dry weight was measured after drying. The crushed and mixed samples were kept in grinding bottles and jars. The site of the experiment is in Sichuan University of China, the GPS coordinates of the experimental site are $104^{\circ} 08^{\prime} \mathrm{E}$ and $30^{\circ} 63^{\prime} \mathrm{N}$.

\section{Methods}

\section{Determination of heavy metal content in water}

The sealed water samples are brought back to the laboratory, and the content of heavy metals in water is measured by flame atomic absorption spectrometry, repeated three times.

\section{Determination of heavy metal content in duckweed}

The nitrate and perchloric acid $\left(\mathrm{HNO}_{3} 40 \mathrm{~mL}, \mathrm{HCLO}_{4} 40 \mathrm{~mL}\right)$ added to $0.3 \mathrm{~g}$ duckweed powder were digested and heated on the electric heating board, and set up to 
$100 \mathrm{~mL}$ by deionized water. The atomic spectrophotometer is used to determine the content by air acetylene flame (Zhao and Shi, 2015).

\section{Determination of chlorophyll content in duckweed}

Plants with good growth and uniform leaf size are selected for continuous cultivation of $3 \mathrm{~d}$ in plastic pots containing tap water (Park and Kim, 2013). They are transferred to 1/10 Hoagland solution for 1 week and treated with Cadmium.

$\mathrm{CdCl}_{2}$ is added to the $1 / 10$ Hoagland solution, and 7 concentration gradients of $\mathrm{Cd}^{2+}$ are set up as 0 (control), 1, 2, 4, 6, 8 and $10 \mathrm{mg} / \mathrm{L}$. Each treatment set up 3 parallel samples with 20 plants. The growth of the plant must be observed during the treatment. The duckweed is cultured in the PGX multi section light culture box. When the light of $4500 \mathrm{lux}$ is irradiated for $12 \mathrm{~h} / \mathrm{d}$, the temperature was $(25 \pm 1){ }^{\circ} \mathrm{C}$, the chlorophyll fluorescence parameters of duckweed after 24, 48, 72 and $96 \mathrm{~h}$ are determined, respectively.

The chlorophyll fluorescence parameters are determined by underwater luminoscope. Before measuring, add duckweed that is sucked out of water into a Petri dish wrapped in tin foil. After 10 mins, the fibers are aligned to the colorimeter and the modulation light is opened to determine the minimum fluorescence (F0). Then the saturation pulse is opened and the maximum fluorescence $(\mathrm{Fm})$ is measured to calculate the maximum light chemical quantum yield (FV/Fm); The photochemical light of setting intensity continuous irradiation time is $3 \mathrm{~min}$, and a saturated pulse $\left(4000 \mathrm{mu} \mathrm{mol} / \mathrm{m}^{2} \mathrm{~s}\right.$ ) with a time interval of $20 \mathrm{~s}$ and a duration of $0.8 \mathrm{~s}$ is opened, then the quenching analysis is carried out. After the determination of the fluorescence parameters, the stable fluorescence value was obtained and analyzed (Lalau and Mohedano, 2015). The calculation formula of chlorophyll fluorescence parameters is as follows (Eqs. 1-7):

$$
\begin{gathered}
F_{V} / F_{m}=\left(F_{m}-F_{0}\right) / F_{m} \\
\Phi_{P S I I}=\left(F_{m}^{\prime}-F_{t}\right) / F_{m}^{\prime} \\
q P=\left(F_{m}-F_{t}\right) /\left(F_{m}-F_{0}\right) \\
r E T R=\Phi_{P S I I} \times P A R \times 0.5 \times 0.84 \\
F_{V} / 2=\left(F_{m}-F_{0}\right) / 2 \\
q N=\left(F_{m}-F_{m}^{\prime}\right) /\left(F_{m}-F_{0}\right) \\
F_{0} / F_{V}=F /\left(F_{m}-F_{0}\right)
\end{gathered}
$$

Where $F_{m}^{\prime}$ the maximum fluorescence output is obtained when the saturation pulse is opened; $F_{t}$ represents the fluorescence output measured at any time; PAR indicates the light and effective radiation intensity $\left(\mu \mathrm{mol} / \mathrm{m}^{2} \mathrm{~s}\right)$ of the incident to the samples.

It should be made clear that the bioaccumulation coefficient is used in the determination. Bioaccumulation coefficient is the ratio of the concentration of certain 
elements or refractory compounds in an organism to the concentration of the substance in the environment in which it exists, and can be used to indicate the degree of biological concentrations. The calculation formula is as follows $(E q .8)$ :

$$
B=\frac{\text { Concentration of refractory compounds }}{\text { Total concentration of substances in the environment }}
$$

The determination of chlorophyll content:

After $96 \mathrm{~h}$, the centrifuge tube containing $0.5 \mathrm{~g}$ samples is frozen in the fridge for $1 \mathrm{H}$, then the $10 \mathrm{~mL} 95 \%$ ethanol heated to $50{ }^{\circ} \mathrm{C}$ in the water bath is added into, and the content of chlorophyll (Tang et al., 2015b) is determined by taking the supernatant in the dark cabinet and taking the supernatant in the dark cabinet. After Shaking and keeping quiet for 3 hours in dark room, the chlorophyll content is measured.

The chlorophyll absorbance $\mathrm{A}$ (Wan and $\mathrm{Wu}, 2018$ ) is determined by spectrophotometer, and the chlorophyll concentration is calculated according to the following formulas (Eqs. 9 and 10):

$$
\begin{aligned}
& \text { Chla }=12.7 A_{663}-2.69 A_{645} \\
& C h l b=22.9 A_{645}-4.68 A_{663}
\end{aligned}
$$

Where Chla and Chlb represent the concentration of chlorophyll a and b (mg/L) respectively; $A_{663}$ and $A_{645}$ mean the absorbance of chlorophyll solution at $663 \mathrm{~nm}$ and $645 \mathrm{~nm}$ respectively. The experimental data are analyzed and processed by SPSS15.0 software.

Enrichment of duckweed response to Cadmium ions in different concentrations of nitric acid solution

The lethal concentration and the actual situation of duckweed in $\mathrm{Cd}^{2+}$ solution are studied. The solution of $1 \mathrm{mg} / \mathrm{L}, 3 \mathrm{mg} / \mathrm{L}$ and $5 \mathrm{mg} / \mathrm{L} \mathrm{Cd}\left(\mathrm{NO}_{3}\right)_{2}$ is disposed by the solid of Cadmium nitrate. The duckweed with good long potential, similar size and fresh weights $1.6 \mathrm{~g}$ is added into the $200 \mathrm{~mL}$ solution of $1 \mathrm{mg} / \mathrm{L}, 3 \mathrm{mg} / \mathrm{L}, 5 \mathrm{mg} / \mathrm{L} \mathrm{Cd}\left(\mathrm{NO}_{3}\right)_{2}$, and the is added to the experiment (Xiong and Jiao, 2014). The other two groups are reserved, repeat it.

\section{Enrichment of duckweed response to Cadmium ions in different periods of time}

The solution of $3 \mathrm{mg} / \mathrm{L} \mathrm{Cd}\left(\mathrm{NO}_{3}\right)_{2}$ is prepared with Cadmium nitrate solution. Duckweed with good growth, similar size and $7 \mathrm{~g}$ fresh weights is placed in the 3 glass cylinders containing $1 \mathrm{~L}$ solution of $3 \mathrm{mg} / \mathrm{L} \mathrm{Cd}\left(\mathrm{NO}_{3}\right)_{2}$, respectively. A glass cylinder containing $1 \mathrm{~L}$ solution of $3 \mathrm{mg} / \mathrm{L} \mathrm{Cd}\left(\mathrm{NO}_{3}\right)_{2}$ without duckweed was also used as a control. The concentration of Cadmium, the chlorophyll content in the duckweed, and the content of Cadmium in duckweed (Allende and Mccarthy, 2014) is measured in turn in the 3 cylinders solution after 4,8 and 12d. The other two groups are reserved, repeat it. 
Determination of relation between heavy metal content in aquatic plants and heavy metal content in water

Duckweed with good growth, similar size and $4.5 \mathrm{~g}$ fresh weights is respectively placed in the 2 beakers containing $600 \mathrm{~mL}$ solution of lake water. Another $600 \mathrm{~mL}$ water beaker without duckweed is used as a control group. The two groups is added with nutrient solution and placed in the place with adequate light and suitable environment (Chen and Liang, 2016). After 4 days, the concentration of $\mathrm{Cu}, \mathrm{Zn}, \mathrm{Ni}$ and $\mathrm{Cr}$ in the solution (Chaudhary and Sharma, 2014) and the chlorophyll content in the duckweed is measured. Another group was prepared, repeat triple times.

\section{Results}

\section{Results of heavy metal content in water}

The contents of $\mathrm{Cu}, \mathrm{Pb}, \mathrm{Zn}, \mathrm{Cd}$ and $\mathrm{Mn}$ in water samples are compared with the standard of Surface Water Environmental Quality (GB3838-2002). The contents of Cu, $\mathrm{Pb}, \mathrm{Zn}, \mathrm{Cd}$ and $\mathrm{Mn}$ in the waters of Taihu Lake $\left(120^{\circ} 36^{\prime} \mathrm{E}\right.$ and $\left.31^{\circ} 22^{\prime} \mathrm{N}\right)$ are described in Table 1.

Table 1. Water quality and heavy metal contents in water and surface water $V(\mathrm{mg} / \mathrm{L})$

\begin{tabular}{c|c|c|c|c|c}
\hline Item & $\mathbf{C u}$ & $\mathbf{P b}$ & $\mathbf{Z n}$ & $\mathbf{C d}$ & $\mathbf{M n}$ \\
\hline Water sample & 7 & 1.02 & 5 & 4 & 4.38 \\
V class standard & 1 & 0.1 & 2 & 0.01 & 1 \\
\hline
\end{tabular}

\section{Analysis of heavy metal content in aquatic plants such as duckweed}

The bioaccumulation coefficient is an important index for measuring the accumulation capacity of heavy metals in plants, the greater the BCF, the stronger the enrichment capacity (Jain and Verma, 2015). The heavy metal content and the BCF of the aquatic plants are described by Table 2 and Figures 1 and 2.

Table 2. Heavy metal content and enrichment factor of aquatic plants such as duckweed $(\mathrm{mg} / \mathrm{kg})$

\begin{tabular}{c|c|c|c|c|c|c}
\hline Name of seed & Position & $\mathbf{C u}(\mathbf{B C F})$ & $\mathbf{P b}(\mathbf{B C F})$ & $\mathbf{C d}(\mathbf{B C F})$ & $\mathbf{Z n}(\mathbf{B C F})$ & $\mathbf{M n}(\mathbf{B C F})$ \\
\hline \multirow{2}{*}{ Water turtle } & Root & $82.04(9.12)$ & $33.74(33.41)$ & $3.21(0.80)$ & $161.59(26.93)$ & $440.26(1.01)$ \\
& Stem and leaf & $23.30(2.59)$ & $5.05(5.00)$ & $1.18(0.30)$ & $54.33(9.06)$ & $104.28(0.24)$ \\
\hline \multirow{2}{*}{ Alternantheraphiloxeroides } & Root & $37.71(4.19)$ & $8.20(8.12)$ & $0.90(0.23)$ & $55.05(9.18)$ & $325.52(0.74)$ \\
& Stem and leaf & $11.83(1.31)$ & $7.32(7.25)$ & $0.84(0.21)$ & $31.47(5.25)$ & $150.22(0.34)$ \\
\hline \multirow{2}{*}{ Chinese arrowhead } & Root & $34.16(3.80)$ & $28.80(28.51)$ & $2.59(0.65)$ & $68.28(11.38)$ & $338.30(0.77)$ \\
& Stem and leaf & $12.75(1.42)$ & $8.27(3.74)$ & $0.62(0.16)$ & $27.62(4.60)$ & $63.65(0.15)$ \\
\hline \multirow{2}{*}{ Reed } & Root & $26.95(2.99)$ & $7.06(6.99)$ & $0.68(0.17)$ & $49.94(8.32)$ & $12.95(0.03)$ \\
& Stem and leaf & $10.91(1.21)$ & $3.78(3.74)$ & $0.36(0.09)$ & $25.75(4.29)$ & $34.72(0.08)$ \\
\hline \multirow{2}{*}{ Zizania } & Root & $54.90(6.10)$ & $16.34(16.18)$ & $1.15(0.29)$ & $60.13(10.02)$ & $73.30(0.17)$ \\
& Stem and leaf & $14.24(1.58)$ & $5.88(5.82)$ & $0.42(0.11)$ & $28.38(4.73)$ & $71.07(0.16)$ \\
\hline \multirow{2}{*}{ Typha } & Root & $22.87(2.54)$ & $5.88(5.82)$ & $0.75(0.19)$ & $41.69(6.95)$ & $24.79(0.06)$ \\
& Stem and leaf & $9.19(1.02)$ & $9.21(9.12)$ & $1.04(0.26)$ & $18.97(3.16)$ & $62.35(0.14)$ \\
\hline Duckweed & Whole plant & $74.25(8.25)$ & $19.35(19.16)$ & $0.90(0.23)$ & $70.15(11.69)$ & $68.30(0.16)$ \\
\hline \multirow{2}{*}{ The lotus root } & Root & $27.20(3.02)$ & $11.21(11.10)$ & $1.12(0.28)$ & $31.02(5.17)$ & $76.99(0.18)$ \\
& Stem and leaf & $9.21(1.02)$ & $2.12(2.10)$ & $0.32(0.08)$ & $24.75(4.13)$ & $74.12(0.17)$ \\
\hline
\end{tabular}




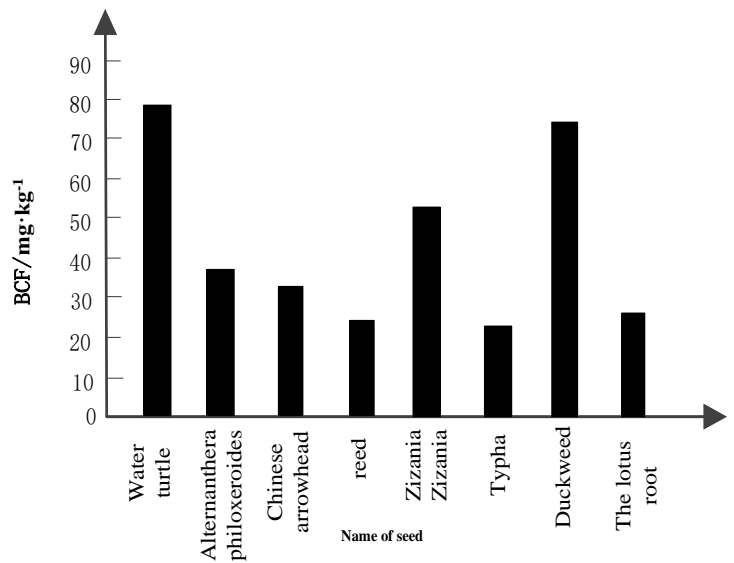

(a) $\mathrm{Cu}$

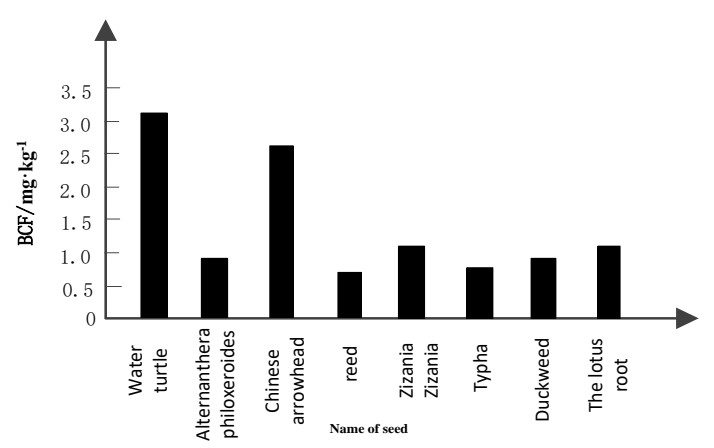

(c) $\mathbf{C d}$

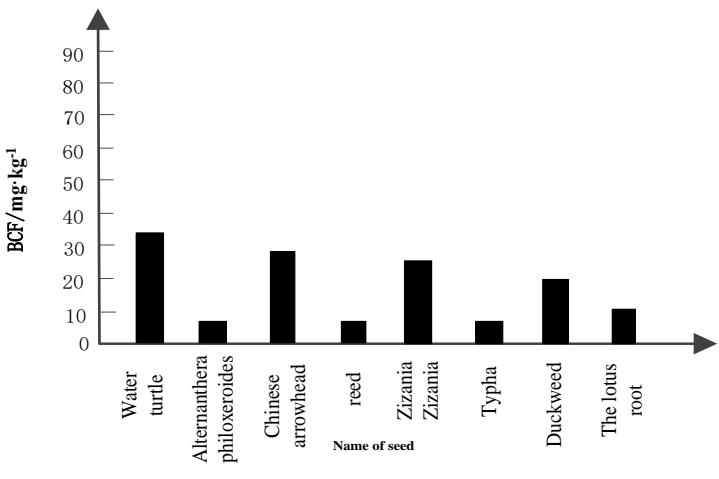

(b) $\mathbf{P b}$

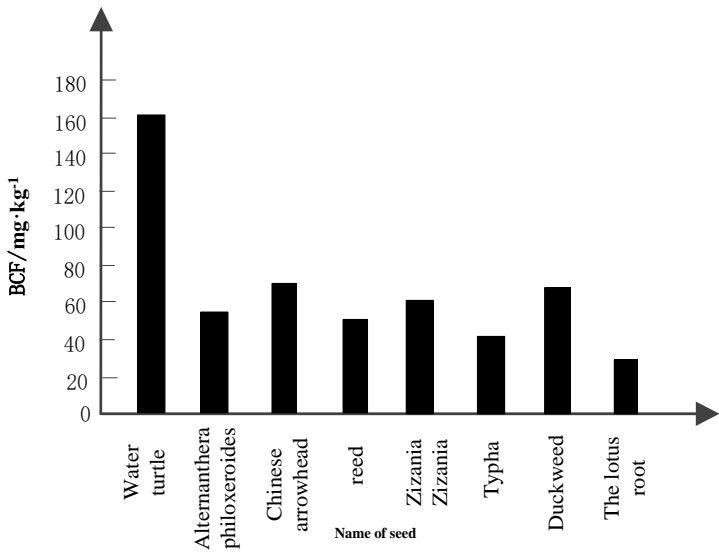

(d) $\mathbf{Z n}$

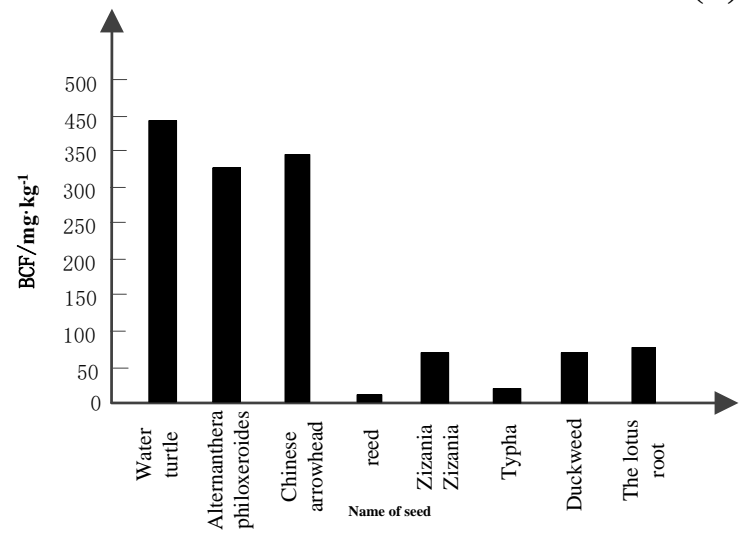

(e) Mn

Figure 1. Contents of heavy metals in the roots of duckweed and other aquatic plants

The relationship between heavy metal content and BCF of the aquatic plants can be seen from Table 2 and Figures 1 and 2. The uptake of heavy metals by different plants is quite different. The accumulation of $\mathrm{Cu}, \mathrm{Pb}$ and $\mathrm{Zn}$ in aquatic plants is relatively large, and the BCF of roots, stems and leaves is all more than 1. It can be seen that the aquatic plants have strong accumulation ability of $\mathrm{Cu}, \mathrm{Pb}$ and $\mathrm{Zn}$, and the accumulation ability of heavy metals in duckweed is generally higher than that of floating plants. According to Table 2 and Figures 1 and 2, compared with other organisms, the contents 
of heavy metals in leaves of duckweed are higher, which indicated that the enrichment ability of leaves of duckweed is stronger.

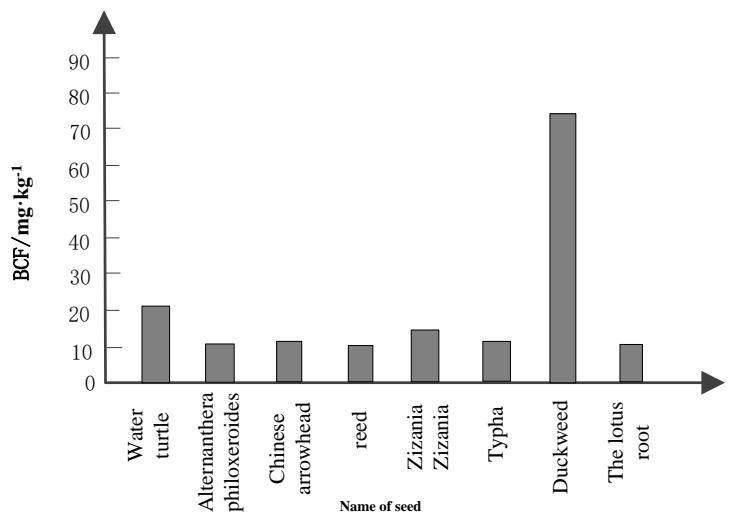

(a) $\mathrm{Cu}$

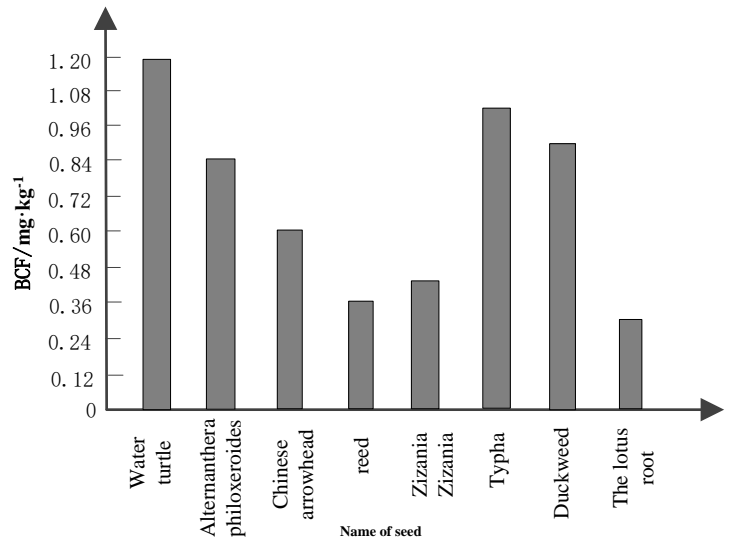

(c) $\mathrm{Cd}$

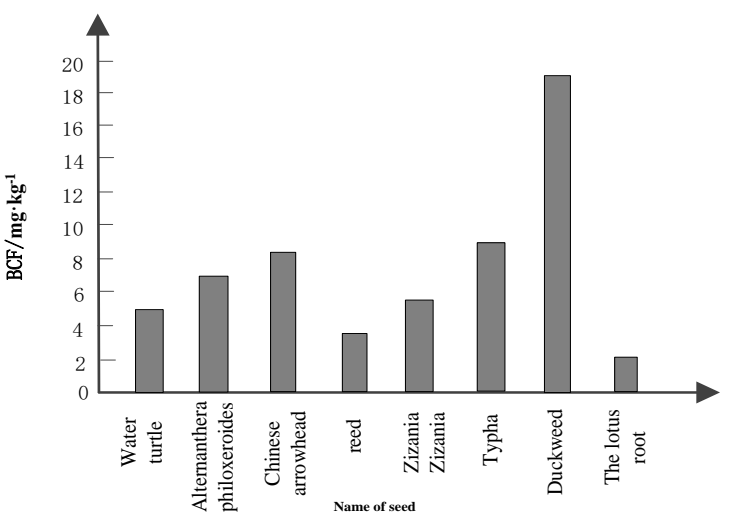

(b) $\mathbf{P b}$

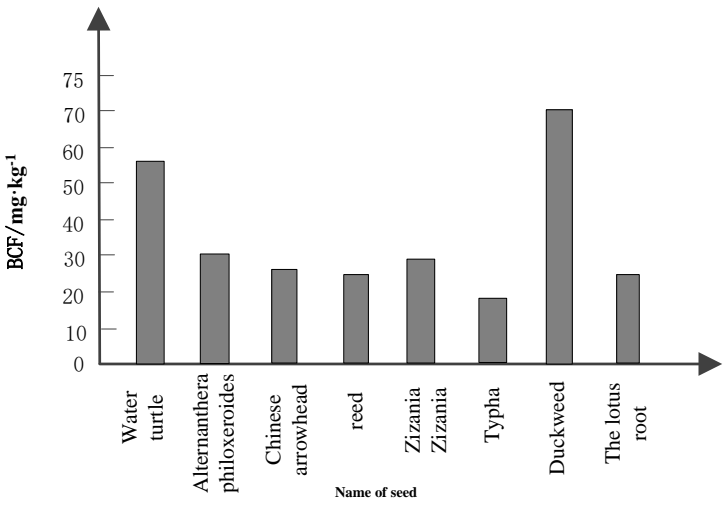

(d) $\mathbf{Z n}$

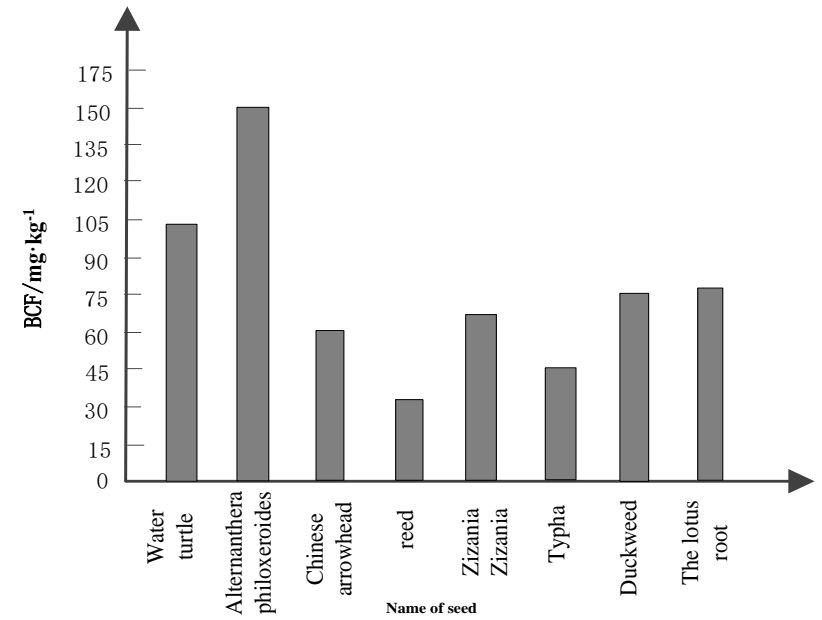

(e) Mn

Figure 2. Contents of heavy metals in leaves and stems of duckweed and other aquatic plants

\section{Determination of chlorophyll content in duckweed}

In order to avoid the inhomogeneity of light in the experiment and the error produced by the instrument debugging (Qiao and Wang, 2015), the data are expressed as relative 
values, that is, the ratio of the chlorophyll fluorescence value measured by the daily Cadmium stress (the following is represented by $0 \mathrm{~h}$ ). In fluorimetric analysis, the maximum photochemical quantum yield $F_{V} / F_{m}$ of PSII is the most commonly used parameter. It reflects the initial light energy conversion efficiency of PSII (PSII apparatus). In normal physiological state, the change is smaller, but it will fall after the plant is stressed (Park and Kang, 2014). Therefore, it is an important parameter for the good environment of plant growth, and could indicate the damage to photosynthesis by Cadmium ions in the short time of the plant being broken. The effects of different concentrations of Cadmium ions on the growth of duckweed are shown in Figures 3 and 4.

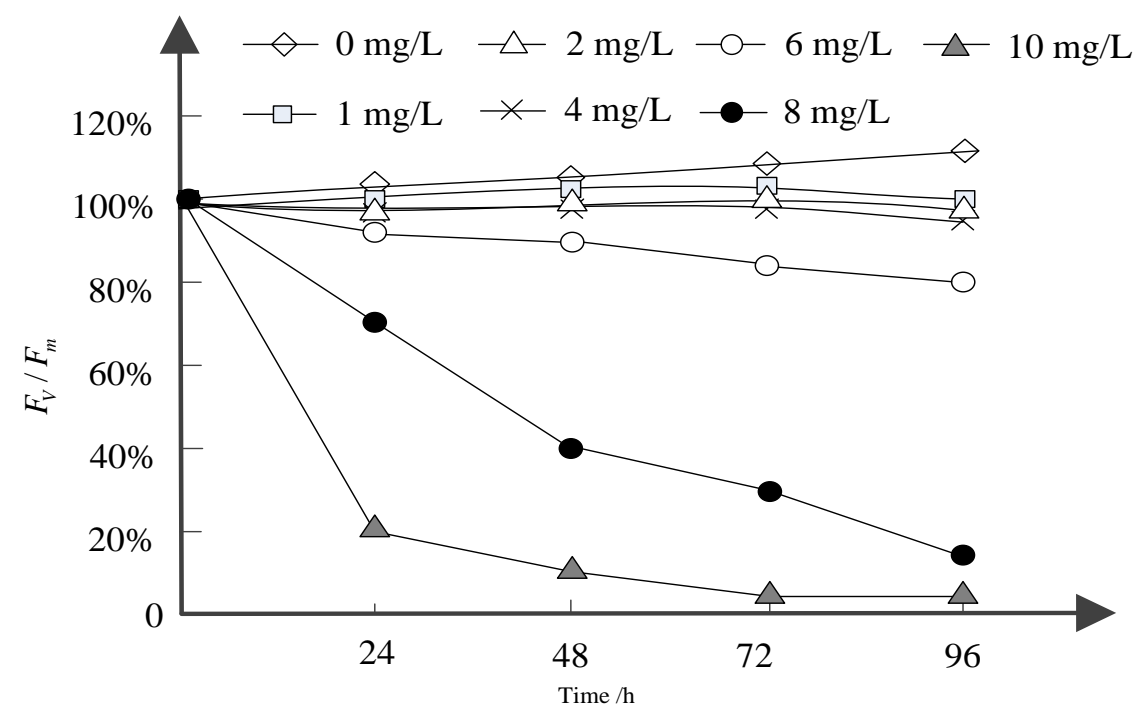

Figure 3. Effect of Cadmium on duckweed $F_{V} / F_{m}$ with different concentrations of Cadmium

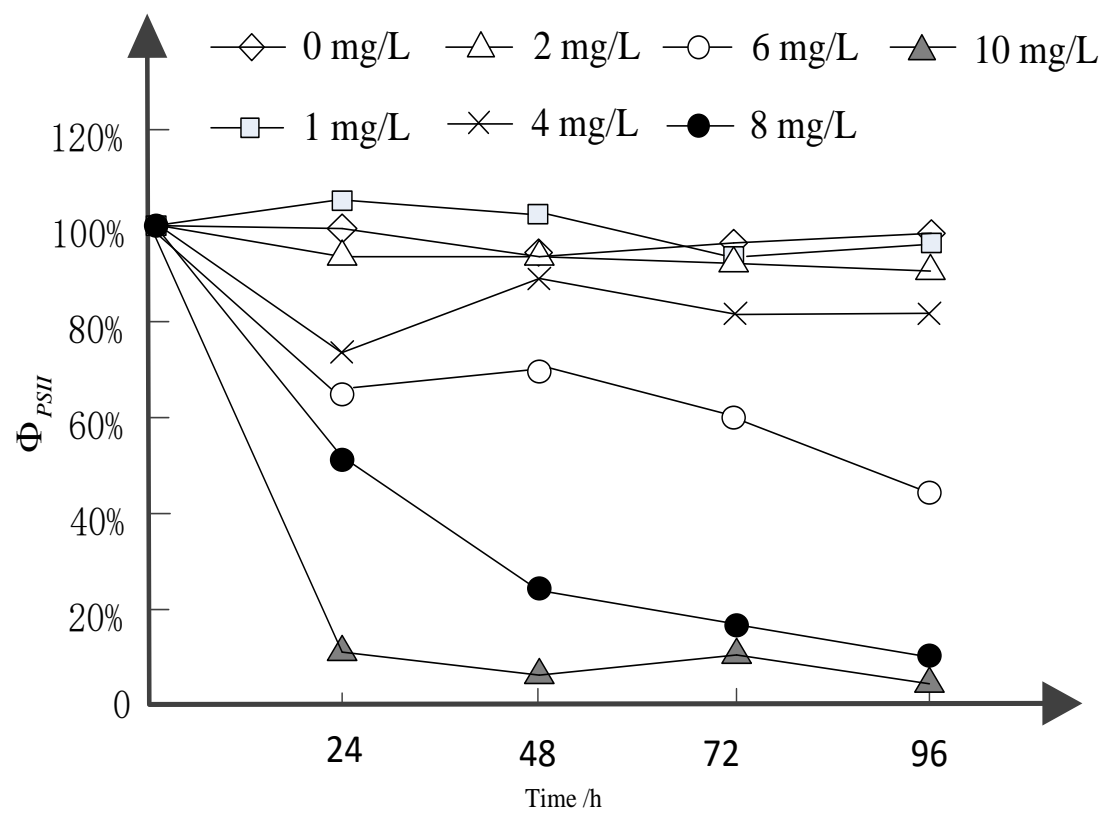

Figure 4. Effect of Cadmium on duckweed $\Phi_{\text {PSII }}$ with different concentrations of Cadmium 
In the experiment, the chlorophyll content of duckweed in different concentrations of Cadmium ion is shown in Figure 5.

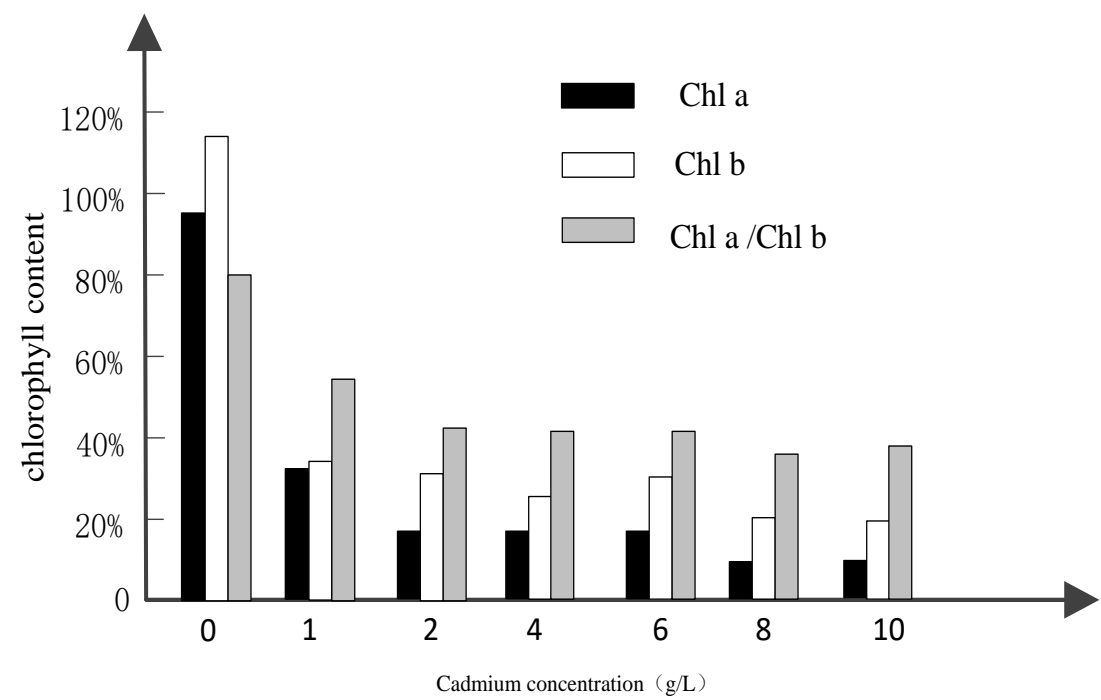

Figure 5. Chlorophyll content of duckweed under different concentrations of Cadmium ions

\section{Enrichment of duckweed in different Cadmium nitrate solutions}

The duckweed is placed in Cadmium nitrate solution of $1 \mathrm{mg} / \mathrm{L}, 3 \mathrm{mg} / \mathrm{L}$ and $5 \mathrm{mg} / \mathrm{L}$ respectively, the experimental results were described in Figure 6.

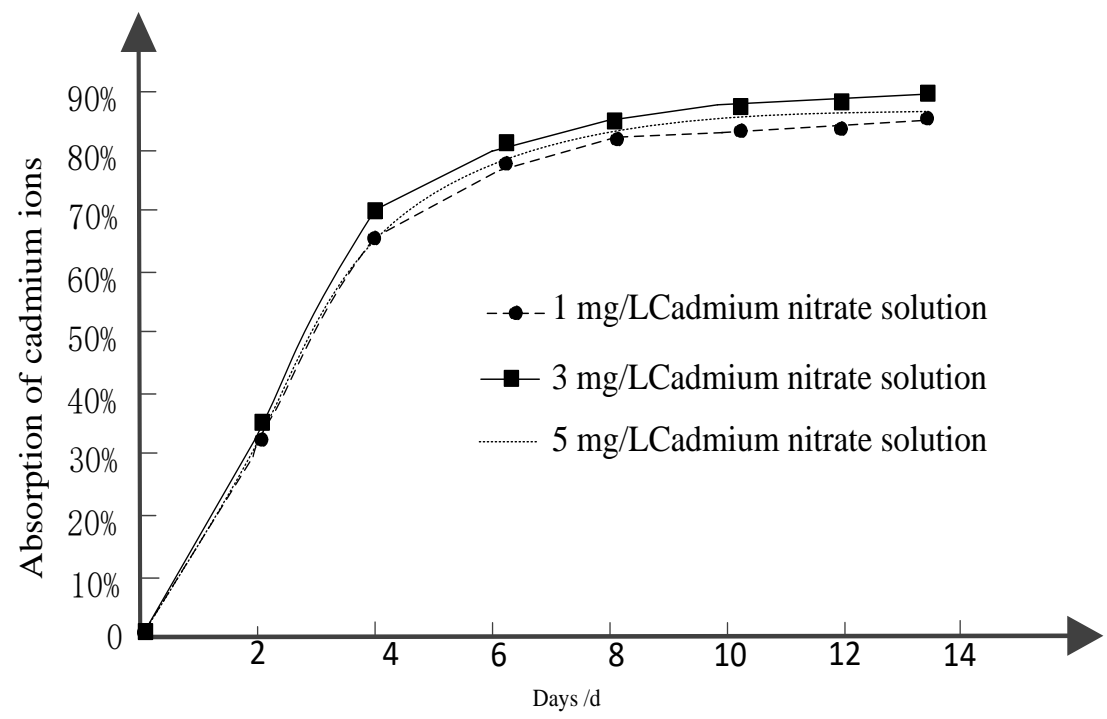

Figure 6. Adsorption of duckweed on Cadmium nitrate solution with different concentrations

\section{Enrichment situation of duckweed response to Cadmium ions in different periods of time}

The concentration of Cadmium ions in the 3 cylinders after $4 \mathrm{~d}, 8 \mathrm{~d}$ and $12 \mathrm{~d}$ are measured by the experiment (Teixeira and Bini, 2017). The relationship between the 
number of experimental days and the enrichment of Cadmium ions is shown by Figure 7.

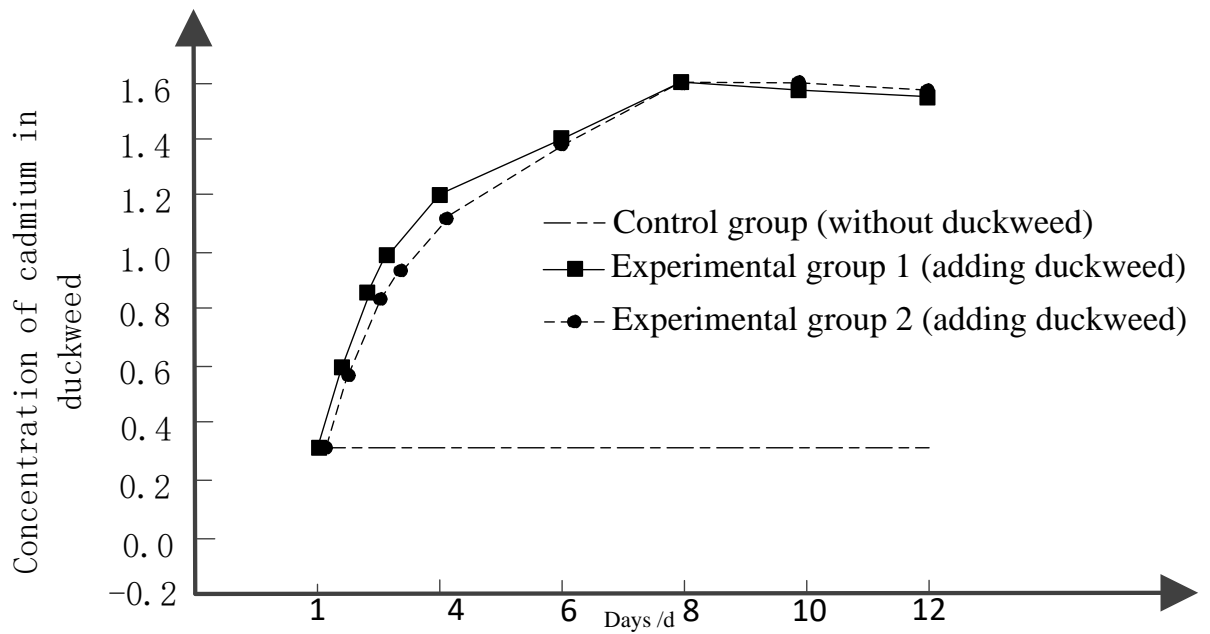

Figure 7. The relationship between concentration of Cadmium and time in duckweed

\section{Relationship between heavy metal contents in aquatic plants such as duckweed and heavy metal contents in water}

Table 2 shows that the average content of heavy metals in different aquatic plants is calculated, and the correlation with the concentration of heavy metals in the water is analyzed (Küsters and Gerhartz, 2015; Gu, 2017), which is described in Table 3.

Table 3. The correlation between the average content of heavy metals and the concentration of heavy metals in aquatic plants such as duckweed and other aquatic plants

\begin{tabular}{c|c|c|c|c|c|c}
\hline \multirow{2}{*}{ Name of seed } & \multirow{2}{*}{ Position } & \multicolumn{5}{|c}{ Correlation coefficient (r) } \\
\cline { 3 - 7 } & & $\mathbf{C u}$ & $\mathbf{P b}$ & $\mathbf{C d}$ & $\mathbf{Z n}$ & $\mathbf{M n}$ \\
\hline \multirow{2}{*}{ Water turtle } & Root & $0.999^{*}$ & $0.997^{*}$ & 0.982 & $0.999^{*}$ & 0.996 \\
& Stem and leaf & $0.999^{* *}$ & 0.971 & 0.996 & $0.999^{*}$ & 0.694 \\
\hline \multirow{2}{*}{ Alternantheraphiloxeroides } & Root & $0.999^{*}$ & 0.922 & 0.786 & 0.919 & 0.983 \\
& Stem and leaf & 0.945 & 0.839 & 0.786 & 0.919 & 0.548 \\
\hline \multirow{2}{*}{ Chinese arrowhead } & Root & 0.875 & 0.996 & 0.945 & 0.689 & 0.949 \\
& Stem and leaf & 0.984 & 0.96 & 0.945 & 0.782 & 0.429 \\
\hline \multirow{2}{*}{ Reed } & Root & 0.998 & 0.885 & 0.945 & 0.835 & 0.631 \\
& Stem and leaf & 0.969 & 0.953 & 0.945 & 0.897 & 0.202 \\
\hline \multirow{2}{*}{ Zizania } & Root & $0.999^{* *}$ & 0.885 & 0.655 & 0.646 & $0.999^{*}$ \\
& Stem and leaf & $0.997^{*}$ & 0.961 & 0.655 & 0.722 & 0.566 \\
\hline \multirow{2}{*}{ Typha } & Root & $0.999^{*}$ & $0.999^{* *}$ & 0.945 & 0.945 & 0.952 \\
& Stem and leaf & 0.945 & $0.999^{*}$ & 0.655 & 0.757 & 0.666 \\
\hline The lotus root & Whole plant & 0.980 & 0.971 & 0.945 & 0.803 & 0.979 \\
\hline & Root & 0.655 & 0.971 & $0.999^{* *}$ & 0.909 & 0.993 \\
& Stem and leaf & 0.907 & 0.971 & 0.655 & 0.982 & 0.016 \\
\hline
\end{tabular}

$* \mathrm{p}<0.05, * * \mathrm{p}<0.01$ 


\section{Discussion}

\section{Discussion on the determination of heavy metal content in water}

In Table 1, the test results of the heavy metal content in water indicated that the content of $\mathrm{Cd}^{2+}$ and $\mathrm{Mn}^{2+}$ in water body is obviously greater than that in other aquatic plants, but the content of $\mathrm{Mn}^{2+}$ in the root of soft shelled turtle is slightly higher than that of water. This is due to the continuous oxidation of plant rhizosphere. the root surface and the root outer body are oxidized to form iron and manganese film, preventing the toxicity caused by excessive absorption of $\mathrm{Cd}^{2+}$ and $\mathrm{Mn}^{2+}$, resulting in the lower content of $\mathrm{Cd}^{2+}$ and $\mathrm{Mn}^{2+}$ in the aquatic plants of duckweed and other aquatic plants. In order to prevent the toxicity caused by excessive absorption of $\mathrm{Cd}^{2+}$ and $\mathrm{Mn}^{2+}$, the iron and manganese films might be formed on the root surface and the root outer body, which led to the lower content of $\mathrm{Cd}^{2+}$ and $\mathrm{Mn}^{2+}$ in the aquatic plants.

\section{Discussion on the determination of chlorophyll content in duckweed}

In Figure 3, when the concentration of Cadmium stress is low $(1,2,4 \mathrm{mg} / \mathrm{L})$, the change of $F_{V} / F_{m}$ is smaller. With the increase of Cadmium stress $(6,8,10 \mathrm{mg} / \mathrm{L})$, the change of $F_{V} / F_{m}$ becomes sensitive. The $F_{V} / F_{m}$ values of 8 and $10 \mathrm{mg} / \mathrm{L} \mathrm{Cadmium}$ stress are decreased by $28.97 \%$ and $75.95 \%$ at $24 \mathrm{~h}$, respectively, and are declined by $74.86 \%$ and $95.95 \%$ at $48 \mathrm{~h}$, respectively. While the concentration of Cadmium is 6 $\mathrm{mg} / \mathrm{L}$, it decreased by $14.95 \%$ at $72 \mathrm{~h}$.

Figure 4 showed the changes of $\Phi_{P S I I}$. The $\Phi_{P S I I}$ changes in the 0,1 and $2 \mathrm{mg} / \mathrm{L}$ groups are small in $24 \mathrm{~h}$, and the $\Phi_{P S I I}$ of $4,6,8$ and $10 \mathrm{mg} / \mathrm{L}$ groups respectively, while that are decreased by $25.49 \%, 33.33 \%, 55.16 \%$ and $85.79 \%$, compared with $0 \mathrm{~h}$. Therefore, the declined of the $\Phi_{P S I I}$ value increased with the increased of $\mathrm{Cd}^{2+}$ concentration, the magnitude of the decreased.

As can be seen from Figure 5, with the increasing of $\mathrm{Cd}^{2+}$ concentration, the contents of chlorophyll a and chlorophyll $b$ are declined significantly, compared with the control group, and the declining of chlorophyll a content is remarkable than that of chlorophyll $\mathrm{b}$, but also the ratio of chlorophyll a to chlorophyll $\mathrm{b}$ is decreased.

This indicated that the decline of chlorophyll $a$ is larger than chlorophyll $b$, which is similar to previous studies (Zhao and Shi, 2015).

\section{Discussion on enrichment of duckweed response to $\mathrm{Cd}^{2+}$ in nitric acid solutions with different concentration}

From Figure 6, it can be seen that the adsorption of $\mathrm{Cd}^{2+}$ on duckweed decreased with increasing concentration. These suggested that $\mathrm{Cd}^{2+}$ is more toxic to duckweed and affects the normal growth of it.

\section{Discussion on enrichment of duckweed response to $\mathrm{Cd}^{2+}$ in different periods of time}

In Figure 7, the concentration of $\mathrm{Cd}^{2+}$ in Cadmium nitrate solution gradually decreased with the increased of treatment time, and the reduction rate of $\mathrm{Cd}^{2+}$ concentration slowed down gradually. 
The concentration of Cadmium in duckweed did not show a monotonous curve with the increase of the processing time, and the concentration of Cadmium in the duckweed reached the maximum $(1.6 \mathrm{mg} / \mathrm{g})$ at 8 days.

\section{Discussion on relationship between heavy metal contents in aquatic plants and heavy metal contents in water}

In the Table 3, the concentration of heavy metals in water is significantly correlated with the concentration of $\mathrm{Cu}, \mathrm{Pb}, \mathrm{Zn}$ and $\mathrm{Mn}$ in aquatic plants duckweed. The heavy metals can be absorbed and accumulated by duckweed. Therefore, the metals sensitivity of duckweed can be used to detect changes of heavy metals in water, which can be used as a bioindicator of environmental pollution.

To verify the effectiveness of this method, the accuracy rate of heavy metal determination in duckweed is compared with Tang et al. (2015a) and Fan et al. (2018). The results are shown in Figure 8.

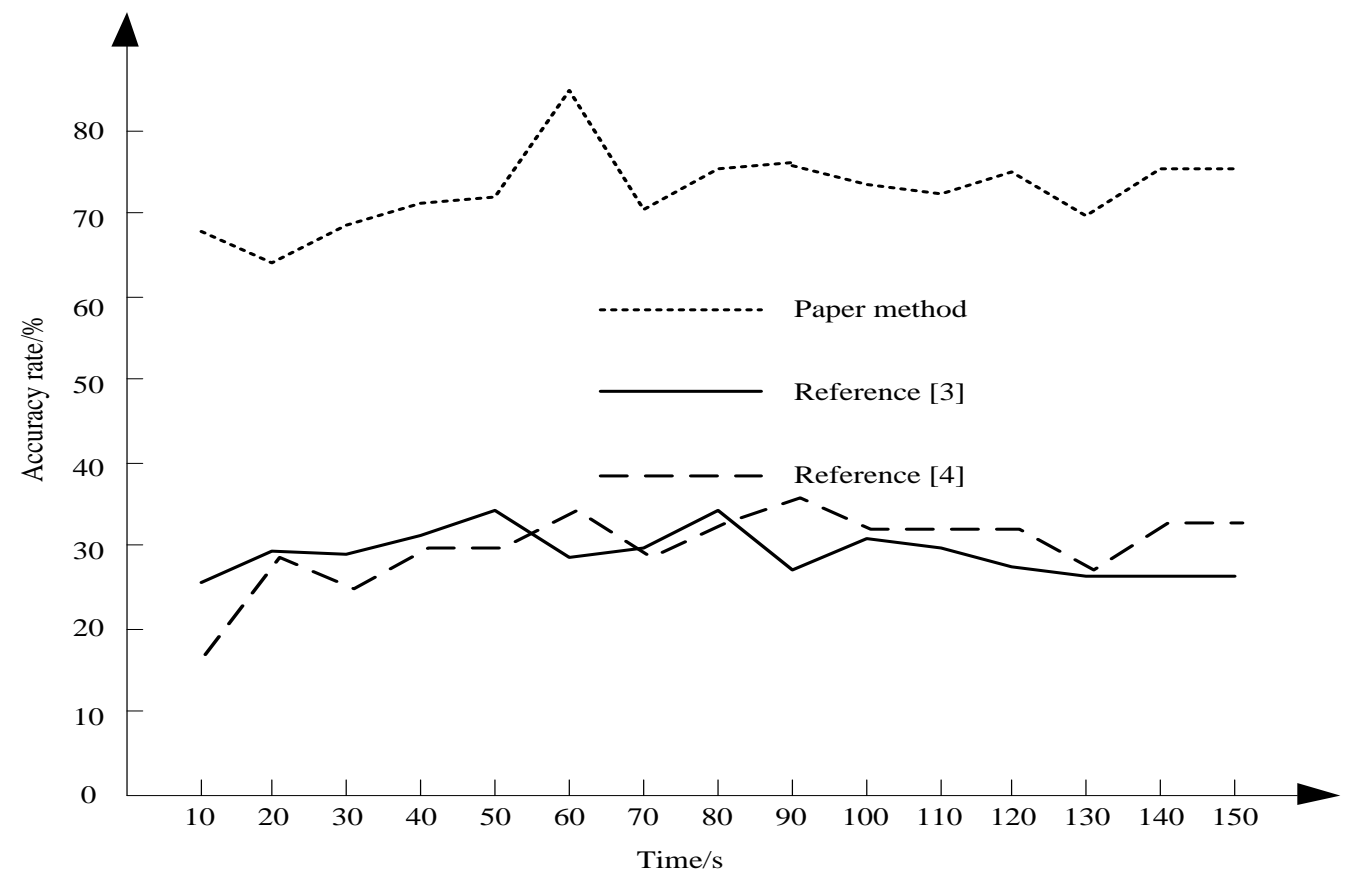

Figure 8. Comparison of accuracy of different methods

According to Figure 8, the accuracy of this method is much higher than that of Tang et al. (2015a) and Fan et al. (2018), and the average accuracy is more than 70\%, while the accuracy of Tang et al. (2015a) and Fan et al. (2018) is less than 30\%.

\section{Conclusions}

In the paper, the enrichment of duckweed response to different heavy metal ions in water is analyzed from the following aspects: the heavy metal content in water, the heavy metal content in duckweed, chlorophyll content, adsorption capacity of Cadmium ions in different concentrations of nitric acid solution, enrichment capacity of Cadmium ion and the relationship between heavy metal content in duckweed and that of water. 
The content of heavy metals in water is measured by flame atomic absorption spectrometry; the atomic spectrophotometer is used to determine the content by air acetylene flame atomic absorption spectrophotometry; the chlorophyll fluorescence parameters and chlorophyll content in duckweed are measured by grinding and underwater luminoscope. Different concentrations of $\mathrm{Cd}^{2+}$ solution are used to observe the lethal concentration and actual situation of duckweed.

Duckweed is cultured in the same concentration of Cadmium nitrate solution, and the enrichment of duckweed response to Cadmium ions in different periods of time is studied.

The average content of heavy metals in different aquatic plants is calculated, and the correlation with the concentration of heavy metals in water is analyzed by setting up the control group.

In short, in order to prevent the toxicity caused by excessive absorption of $\mathrm{Cd}^{2+}$ and $\mathrm{Mn}^{2+}$, the iron and manganese films are formed on the root surface and the root outer body, which led to the lower content of $\mathrm{Cd}^{2+}$ and $\mathrm{Mn}^{2+}$ in the aquatic plants. The aquatic plants have strong accumulation ability of $\mathrm{Cu}, \mathrm{Pb}$ and $\mathrm{Zn}$, and the accumulation ability of heavy metals in duckweed is generally higher than that of emergent plants. With the increased of $\mathrm{Cd}^{2+}$ concentration, the content of chlorophyll a and chlorophyll $b$ significantly decreased, compared with the control group, and the declined of chlorophyll a, but the chlorophyll $\mathrm{b}$ content increased. The absorption rate of Cadmium nitrate solution at $3 \mathrm{mg} / \mathrm{L}$ is the largest, reaching $87 \%$, and the adsorption of $\mathrm{Cd}^{2+}$ on duckweed decreased with increasing concentration. The concentration of Cadmium in duckweed did not show a monotonous curve with the increased of the processing time, and, the concentration of Cadmium in the duckweed reached the maximum $(1.6 \mathrm{mg} / \mathrm{g})$ at the 8 days. The concentration of heavy metals in water is significantly correlated with the concentration of $\mathrm{Cu}, \mathrm{Pb}, \mathrm{Zn}$ and $\mathrm{Mn}$ in duckweed. The heavy metals can be absorbed and accumulated in the duckweed, and the absorption of heavy metals varies with the change of water environment.

As a new green pollution control technology, phytoremediation is still in the experimental research stage. There is still much work to be done in order to be widely used in wild.

(1) Strengthen the mechanism of metal removal by microbes and plants. The ecological and physiological characteristics of plant communities combined with plant roots, the role of root exudates in the selection of microbial communities and the mechanism of interaction between plant roots and rhizosphere microbial communities need to be further studied.

(2) In the future, genetic factors of superaccumulative plants or microbes growing in heavy metal contaminated environments will be applied to non-superaccumulative plants or microbes through transgenic technology; therefore, it is possible to develop super-enriched plants with strong adaptability, large biomass and enrichment ability to various target pollutants.

Acknowledgements. The authors acknowledge financial support received from the National Key Technology R\&D Program of China (No. 2015BAD15B01); The Projects of International Cooperation of Ministry of Science and Technology of China (No. 2014DFA30680); Key Laboratory of Environmental and Applied Microbiology, Chengdu Institute of Biology, Chinese Academy of Sciences (No. KLCAS2014-02); West Light Foundation of the Chinese Academy of Sciences (Y2C5021100). 


\section{REFERENCES}

[1] Allende, K. L., Mccarthy, D. T., Fletcher, T. D. (2014): The influence of media type on removal of arsenic, iron and boron from acidic wastewater in horizontal flow wetland microcosms planted with Phragmites australis. - Chemical Engineering Journal246(12): 217-228.

[2] Chaudhary, E., Sharma, P. (2014): Assessment of heavy metal removal efficiency of lemnaminor. - Archiv der Pharmazie 302(12): 897-899.

[3] Chen, Y., Liang, Y., Zheng, Z.-Q. (2016): Effects of aging effect of duckweed biochar on its properties and adsorption on Cd (II). - Environmental Engineering 34(10): 60-64.

[4] Fan, Y., Zhu, J., Zhang, Y. et al. (2018): Effect of phosphate on oxidation resistance and uranium enrichment of duckweed. - Anhui Agricultural Science (12): 12-13.

[5] Gu, Z. (2017): Study on the status quo of heavy metal pollution in water body and the pollution control of duckweed. - Engineering Technology 62(1): 65-71.

[6] Jain, R., Verma, R., Singh, A. (2015): Influence of selenium on metallothionein gene expression and physiological characteristics of sugarcane plants. - Plant Growth Regulation 77(2): 109-115.

[7] Küsters, M., Gerhartz, M. (2015): Enrichment and low-level determination of glyphosate, aminomethylphosphonic acid and glufosinate in drinking water after cleanup by cation exchange resin. - Journal of Separation Science 33(8): 1139-1146.

[8] Lalau, C. M., Mohedano, R. A., Schmidt, É. C. et al. (2015): Toxicological effects of copper oxide nanoparticles on the growth rate, photosynthetic pigment content, and cell morphology of the duckweed Landoltiapunctata. - Protoplasma 252(1): 221-229.

[9] Li, S., Wang, W., Liang, F. (2016): Heavy metal removal using nanoscale zero-valent iron (nZVI): Theory and application. - Journal of Hazardous Material 322(Pt A): 163-171.

[10] Park, J. A., Kang, J. K., Kim, J. H. (2014): Transport and removal of bacteriophages MS2 and PhiX174 in steel slag-amended soils: column experiments and transport model analyses. - Environmental Technology 35(10): 1199-1207.

[11] Park, S., Kim, K. S., Kang, D. (2013): Effects of humic acid on heavy metal uptake by herbaceous plants in soils simultaneously contaminated by petroleum hydrocarbons. Environmental Earth Sciences 68(8): 2375-2384.

[12] Qiao, X., Wang, P., Shi, G. (2015): Zinc conferred Cadmium tolerance in Lemna minor, L. via modulating polyamines and proline metabolism. Plant Growth Regulation 77(1): 1-9.

[13] Tang, L., Fang, Y., Jin, Y., et al. (2015a): Selection of heavy metal Cadmium superenriched duckweed varieties and their removal effect on Cadmium in water. Journal of Applied and Environmental Biology 21(5): 830-836.

[14] Tang, L., Fang, Y., Jin, Y. (2015b): Screening of Cadmium enriching duckweed and its removal effect on Cadmium in water. - Journal of application and Environmental Biology 21(5): 830-836.

[15] Teixeira, M. C., Bini, L. M., Thomaz, S. M. (2017): Biotic resistance buffers the effects of nutrient enrichment on the success of a highly invasive aquatic plant. - Freshwater Biology 62(1): 65-71.

[16] Unsal, Y. E., Soylak, M., Tuzen, M. (2015): Determination of lead, copper, and iron in cosmetics, water, soil, and food using polyhydroxybutyrate-B-polydimethyl siloxane preconcentration and flame atomic absorption spectrometry. - Analytical Letters 48(7): $1163-1179$.

[17] Wan, H., Wu, Y., Qin, H.-J. (2018): Review on water environment restoration and resource utilization of duckweed plants. - Jiangsu Agricultural Sciences 46(2): 6-10.

[18] Xiong, J., Jiao, C., Li, C. (2014): A versatile amphiprotic cotton fiber for the removal of dyes and metal ions. - Cellulose 21(4): 3073-3087.

[19] Zhao, Z., Shi, H., Duan, D. Z. (2015): Title: The influence of duckweed species diversity on ecophysiological tolerance to copper exposure. -Aquatic Toxicology 164: 92-98. 